\title{
Some complications of the transitive society in the sphere of legal education
}

\author{
Anastasia Kovaleva $^{1 *}$, Victoria Rodina $^{1}$, and Olga Volkonskaya $^{2}$ \\ ${ }^{1}$ Don State Technical University, department "Criminal Law and Criminalistics", 344000 \\ Rostov-on-Don, Russian Federation \\ ${ }^{2}$ Don State Technical University, department "World languages and cultures", 344000 \\ Rostov-on-Don, Russian Federation
}

\begin{abstract}
A transitive society is a special stage of its development, which is influenced by various factors that ultimately affect the direction of development of the society, whether it is positive or negative, will move to a new higher stage of development or an irreversible process of degradation will begin. The transition period in Russia has its own peculiarities, largely due to the original historical path and profound transformations that took place one after another for a long period. However, the formation of these institutions is impossible without legal education, the highest degree of which provides access to higher legal education. The aim of this research is to make an objective assessment of the situation in the system of higher legal education, to analyse its problem areas and to assess their impact without overcoming the transitional period of State development.
\end{abstract}

\section{Introduction}

A huge number of studies of the specialists - representatives of various sciences have been devoted to the study of peculiarities of the development of any sphere of human life during the period of the state's transitional changes. Most of these studies demonstrate transitional states, phenomenological gaps, and similar categories. Also, almost all scientists, in one way or another affected the period of transit in their works, payed their attention to the fact that such transitional periods in any case are associated with overcoming periods of contradictions and the influence of such a factor as temporality.

The peculiarity of the transitive society, which developed in modern Russia, is often characterized by the use the concept "risk society" [1], which has already become established. The concept of "risk society" itself implies the notion of a society in transition, as a creative or destructive version of it. The so-called creative societies carry out the transition to a higher stage of development and modernization, grow their potential.

Societies of destructive type, in turn, can be characterized through progressive regression, gradual destruction of the positive possibility of the social changes. In this case, the

\footnotetext{
* Corresponding author: a.kovaleva-1@yandex.ru
} 
existential resource of such states is reduced, which ultimately leads to their complete disappearance (as social integrity) from the international arena.

The provisions of this concept have been developed for the conditions through which Western States pass, moving to a higher stage of modernization, but they could be completely applied to the situation that is developing in our country. Modern Russia can be characterized through the following distinctive features:

- $\quad$ hereditary vestiges, which, first of all, can be represented through communist "modernization" - partial, instrumental, imposed from above and which should be realized;

- negative dynamics in the sphere of accumulation of social wealth, which is supported by negative tendencies in the production and distribution of risks, and as a result - destruction of already existing, accumulated wealth on the scale of the country;

the pervasive nature of modern risks (in contrast to the initial stage of development, when one part of the society receives profit from the process and the result of the production of risks, and the other - suffers from them).

The process of scaling up the risk production is a catalyst for deformation and (more often) tightening of the social structure of society and the existing political regime.

The ideal that the "risk society" inevitably aspires is security, which, in modern Russian realities, can be formulated as double or sometimes triple security. Thus, there is a situation in which the "unequal society" that previously existed with its own system of values and priorities was transformed into "unsafe society".

\section{Results and discussion}

However, the understanding of the situation of demoderization and the concentration of destructive processes, prevailing in the Russian Federation, will be superficial if we don't pay attention to the underlying risks of the social sphere. By social risks we understand the risks that are generated by the processes of vital activity of the society itself, by its changes, both functional and structural, and ultimately by the transition of the whole system of society to a completely new state. These risks include:

- the dominant set of fundamental social attitudes that were generated and cultivated by the dominant ideology;

- the specific perception of the society, as well as the attitude toward the surrounding world;

- social dynamics based on rapid and fundamental changes or the disintegration of existing social system, territorial communities and other forms of life organization;

- the presence of hazards of different kinds for human's life in its environment;

- dynamic changes and restructuring of the whole country.

A rather long period of staying in the conditions of such system has formed people's mind, especially those who remember the Soviet period of our country's history, negative attitude and rejection of any social changes that are promoted "from above". This is fully applies the changes that have accompanied our country recent years, which were a complex and largely contradictory process aimed at destroying of the Soviet system's surviving, and on the other hand, the accumulating and further using the products of the Soviet system's collapse in order to build a new variant of clan-corporate society. This dynamic, regardless of the specific society, is often accompanied by the exposure of the structures that can be described as feudal-bureaucratic and criminal.

The phenomenon of transitivity in Russia has chronologically coincided with the period of increasing the intensity of absolutely all processes in society, the widespread popularization and increasing the use of high technologies and maximization of the availability and speed of information dissemination. These processes created new 
requirements for the higher education, which, despite all the fundamental changes, did not lose its position as one of the most important and demanded social institutions.

The system of higher education is essentially designed to ensure, in the context of existing society, the preservation, development, multiplication and transfer of achievements of both material and spiritual culture from one generation to another. It is the system of education that is designed to raise a new generation and prepare it for successful selfrealization, fruitful life from the realities of the existing society, and also to form in the younger generation a desire and an opportunity for modernizing this society and its transition to the qualitatively new higher level. However, such a high goal inevitably faces serious problems that affect the very essence of education.

Nowadays, in our opinion, an absolutely universal problem for the new emerging system of higher education is the creation and implementation of a new philosophy of education. Such a process involves a comprehensively studied and justified selection of meaningful characteristics of general cultural and professional training of young personnel, creation of innovative pedagogical technologies, taking into account the possibility of their real application in the process of realization of the educational process. It becomes especially relevant in the context of discussions about legal education, which is called to form not only the dry knowledge of the norms of law and the algorithmic skills and rules of their application, but to lay the fundamental ideas about good and evil, law and justice, truth, ways of its comprehension and the possibility of achieving it.

The law as a phenomenon of the human community is characterized by all common features inherent in all social institutions, such as the presence of specific functions, normative characteristics, cultural and ideological symbols, structuring. The law is the most important factor of social order, at the same time its regulator and guarantor. It is intended to ensure social stability, warning each individual and the whole society against any kind of destructive vectors, while preserving, ensuring and protecting the dynamic nature of social relations. The norms of law perform a regulatory function, covering absolutely all spheres of public life, and therefore directly affect the process of controlling the activities of state bodies, institutions, organizations and their employees. At the same time, it is necessary to understand that that the law acts as a necessary part of social control, gives it the opportunity to exist as a whole, regulates it and protects it. Also, the law is inextricably linked with the current political life of the state, acting as an instrument of politics. And, in addition to all of these, law is an element of a holistic, historically developed system of the society's values, on the one hand, and on the other - reflecting the values of the orientation and attitudes of the society in which it exists.

In order to understand better why legal education takes special place in the system of higher education and in the public structure of society, it is necessary to distinguish a set of functions that are performed by the right as a special kind of social institution:

1. The integral function is realized through the organization and maintenance, regardless of the changing external factors, of a legal order that would completely permeate the society and bind it, without giving centrifugal forces to separate it. Only through the existence and healthy functioning of legal norms in the state, it is possible to achieve the emergence and permanent existence of trends in the prevalence of creative beginnings over tendencies to destruction and anomie. Ensuring the possibility of a society as a stable system and adapting it to the changing objective realities of the modern world is due to the presence and maintenance of a certain "harmless" level of conformity in society.

2. The regulatory function of law puts it in a kind of lever that governs all the processes taking place in a particular society. It is quite natural that the law contains a certain trajectory of behavior and prescribes not only to the individual, but also to the group to observe these prescriptions. This together with the integrative function contributes to the consolidation of already established social relations, their improvement, 
development, which should eventually lead to the harmonious functioning of the social organism.

3. The protection function is closely related to the regulatory function already considered and is aimed at the comprehensive protection of individuals, their associations and society as a whole from any violation of their rights and legitimate interests. This function of law is implemented through the establishment of certain prohibitions on those acts (both actions and omissions) that the state considers as undesirable and its consequence - as a threat to one or another sphere. Moreover, the imposition of such prohibitions is accompanied by security measures in the form of a prescribed punishment for the violation of one of the prohibitions. In addition, the rights and interests of the affected persons, as well as the restoration of the rights of those who have been unlawfully or unreasonably accused of misconduct or crime, are a subject to compulsory restoration within the protection function.

4. The communicative function of law is a process of coexistence of law together with all other social institutions in the information space of society. This task becomes especially problematic during the transit period when the transition from one established system of society to a new one, which often implies the root break of the outdated system of social institutions to a new, perhaps consisting of innovative institutions which effectiveness hasn't still checked.

5. The social function, which can be presented as a direct continuation of the integrative function we have already considered, plays a major role in instilling social values, norms established in society, allowing it to maintain its healthy state and normal functioning. In order the process of socialization should be effective and stable, it is necessary for the young generation to acquire deeply, fully and without distortion the social and legal values and norms aimed at maintaining social order in the state.

This process, in particular, is intended to facilitate the acquisition of a legal education. Despite the fact that the process of the individual's socialization lasts all life, its foundations are laid at a young age. The result of each stage of this process is the formation of an internal imperative regulator, without any external influence prevents the manifestation of undesirable deviant behavior or, on the contrary, stimulates positive behavior from the point of view of the society. The socialization of the individual is carried out through the institution of law, which is realized through legal education at various levels (whether it is the common level of perception of norms, including in the family, in the circle of communication, or professional - in the context of higher education). The result of effective legal education is formed legal consciousness and a high level of legal culture.

Legal education differs from other spheres, it is not only intended to instill an understanding of the norms formed in society and regulating it, but also is obliged to form a level of legal awareness, legal culture, morality, justice and objectivity among students that would allow them to directly participate in the formation of such norms that would not only regulate social relations, but also create the conditions for their development, and the transition of the state to a higher level of development. Thus, the correlation between legal education and the existence of society at its transit stage becomes objectively understandable. Therefore, it seems necessary to identify the main problems faced by the modern legal entity in Russia, which exists during the transformation period.

According to the data from the bulletin " Higher Education Reform: Domestic and Foreign experience" published on July 06, 2018 on the official website Of The Analytical Center under The Government of the Russian Federation, more than $20 \%$ of teachers at Russian universities would like to change the scope of their activities, which they associate with a significant decrease in wages [2]. In other words, the social and political realities of modern Russian society aren't so favorable to attract qualified personnel to the higher 
school. At the same time, this is accompanied by a sharp process of increasing the average age of the teaching staff of the higher educational institutions in our country. For the sake of justice, it should be noted that this trend is characteristic not only for legal universities, but for the entire system of higher education. However, this fact doesn't make the situation more rosy and directly points to dangerous vectors of development, connected with the loss of the existing school, the interruption of the transfer of the accumulated knowledge. It is well known that the greatest scientific and cognitive activity is associated with the age of 30-40 years, followed by a decline in scientific activity, which is associated with the beginning of the process of gradual extinction of nerve cells.

The deep-rooted cause of this situation is a systemic, permanent underfunding of the educational and scientific sphere as a whole, and the insufficient level of the teacher's remuneration. This problem is evident especially during the comparison official data on salaries of representatives of the authorities in Russia, the judicial system, law enforcement bodies and the representative of the teaching community [3].

Another reason for this deplorable situation related to the teaching staff was the policy of the state in the field of education. In accordance with the "road map" of education [4], which was approved in 2013 by the Government of the Russian Federation, the norms for the number of teaching staff per unit of students (12 teachers per 1 student) are defined, which inevitably led to a reduction of the number of teachers for about $40 \%$. Our conclusions are confirmed by official data given by Rosstat [5], according to data for 2016, a reduction of university teachers by 81 thousand people was implemented, which was $26 \%$ of their number in 2012.

We would particularly like to note that the quantitative indicators considered aren't based on any fundamental research or calculations, it may be tacitly accepted from the experience of Western countries, but don't take into account assistants, postdocs (from 2 to 12 per professor) who conduct classes for professors and associate professors (Fig. 1).
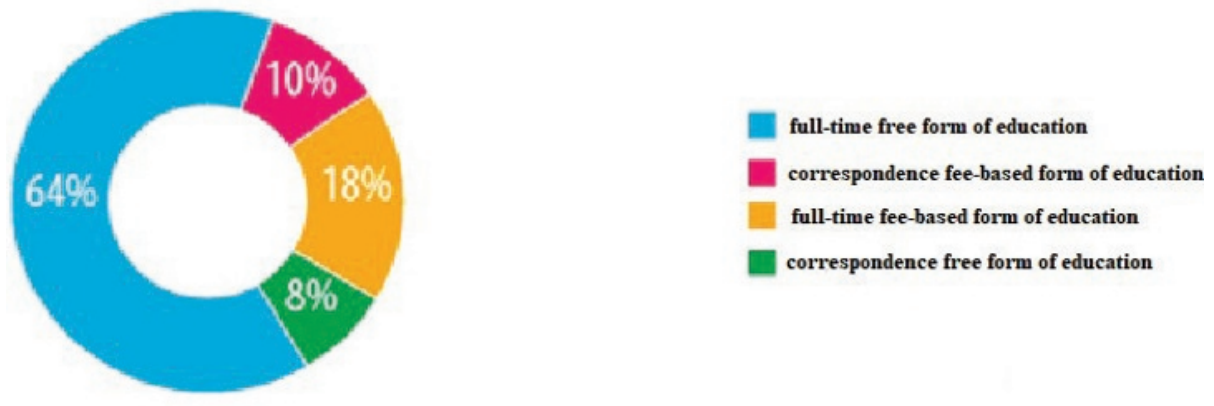

Fig. 1. Forms of training in legal programs.

Another important problem of the system of the higher legal education was the actual increase in the educational load of teachers and the appearance of all kinds of additional work. At that time the Ministry, called the Ministry of Education and Science of the Russian Federation (now the Ministry of Science and Higher Education of the Russian Federation), determined the limit level of the teacher's load for 900 hours [6], while leaving behind them the obligation to prepare students for participation in competitions, olympiads, conferences and so on beyond this standard. At the same time, the structural load of the teacher consists in the overwhelming majority of the audit load, which involves direct contact with the trainees. At the same time, in order to determine at least approximately the volume of the load that lies on the shoulders of the teacher, it is necessary to point out that; approximately, every tenth of today's students is a lawyer student. Every year, about 200 
thousand graduates in the legal sphere are issued from the walls of legal universities.

Training in legal specialties is implemented in every second university (branch) of the country, while half of them do not provide the budget forms education for lawyers. The majority of students receive fee-based form of education ( $82 \%$ of all). Only $10 \%$ of all legal students have the opportunity to receive full-time free form of education.

\section{Conclusions}

The popularity of legal education has not been declining for many years, which is an absolutely logical explanation, based on the idea that the profession of a lawyer really developed in the society. First, the legal profession is traditionally considered more profitable, which is confirmed by the official data of Rosstat. Secondly, legal education provides an advantage even if a future graduate decides to realize himself in a different field. This situation is traditionally associated with developing countries, such as Argentina and China, which also have a huge number of young people who want to get a law degree.

According to statistics, over the past 20 years, approximately 2 million people have received legal education in Russia, but only about 300 thousand people have found work in their specialty. And even if we make an intentional assumption and assume that approximately the same number of the legal graduates work in law firms or are private lawyers, this will not affect the general conclusion that most students sought to get a law degree "for show".

Of course all this conclusions can't have a positive effect either on the existing system of legal education, nor on the development of legal culture and legal consciousness, or the development of society as a whole, especially taking into account the peculiarities of its development in the transitional period. Thus, the state of law and, accordingly, the legal education in Russia is inextricably linked with the political and economic problems facing the country in the transition stage of development. The existence of these problems reduces the effectiveness and potential of the institution of law. In many ways, one can see the fault of the political elite of the country, whose activity does not always comply with legal norms.

\section{References}

1. See: Yanitsky O.N. Modernization in Russia in the light of the concept of "risk society", Polis, 6, 21-48 (1995).

2. Education Bulletin. Reform of higher education: Domestic and foreign experience, URL: Http://ac.gov.ru/files/publication/a/13584.pdf.

3. Decree of the President of the Russian Federation of 07.05.2012 No. 599 "ON measures to implement the state policy in the field of education and science", $\mathrm{CZ}$ of the Russian Federation, 19, 2336 (2012).

4. Order Of The Government of the Russian Federation of 30.04.2014 No. 722-r "On the approval of the plan of activities ("road map") "Changes in the sectors of the social sphere aimed at improving the efficiency of education and science" of the Federal Assembly of the Russian Federation, 19, 2469 (2014).

5. Balatsky E. Salary impasse. Where will the Roadmap come from?, Science. Innovation. Education, 1(23) (2017).

6. Letter of the Ministry of Education of the Russian Federation of 26.06.2003 No. 14- 55-784 / 15 "On approximate standards of time for calculating the volume of educational work and the main types of educational-methodical and other works performed by the teaching staff of educational institutions of higher and additional 
professional education", Official documents in education, 23 (2003). 